\title{
On the Function and Exertion of Management in Architectural Curtain Wall Design
}

\author{
Mengqi Hao*
}

Yuanyang Architecture Co., Ltd. E-mail: mengqi@qq.com

Abstract: Curtain wall structure is the common type of external fixation structure of high-rise and super-high-rise buildings. The application advantages of curtain wall structure have been paid attention to by engineers, so its application is more and more extensive. Based on this, this paper briefly expounds the basic concept of curtain wall, and puts forward the development strategy of management work in building curtain wall construction, aiming at deeply analyzing the current situation of building curtain wall construction in China and deeply exploring the role of management work in building curtain wall construction stage from the project management level.

Keywords: Building Curtain Wall; Construction Management; Engineering Material

\section{Introduction}

Curtain wall is the most commonly used material for the facades of high-rise buildings and super high-rise buildings. The curtain wall structure has thermal insulation performance, sound insulation performance, aesthetics and construction convenience, and the construction of curtain wall is an independent project. After structural designers embed embedded parts in the building frame, the curtain wall construction team can directly hoist the curtain wall for installation. Studying the application points and management of curtain wall construction technology is the work that must be focused on in the early stage of curtain wall construction activities, and it is also the key work to significantly improve the quality of curtain wall construction.

\section{The basic concept of curtain wall}

According to the different materials of curtain wall panels, curtain walls can be divided into glass curtain walls, stone curtain walls, aluminum curtain walls and metal curtain walls. The characteristics of curtain wall are summarized as follows: The curtain wall structure has a relatively complete structural system, and the curtain wall panel is connected to the supporting structural system by bolts, and the supporting structural system is connected to the main structural system of the building by embedded parts; The curtain wall is mainly subjected to wind load, earthquake and temperature, and because the curtain wall structure system is connected with the main structure of the building, the load can also be transferred to the main structure of the building; The curtain wall supporting structure system is mainly composed of steel keel. Under the action of load, the curtain wall supporting structure system has the ability to deform itself in plane and out of plane, so it is allowed to have certain displacement; The curtain wall can refract the color of the sky, show different patterns through preset light strips, and promote

Copyright (C) 2020 Mengqi Hao

doi: 10.18282/adr.v2i1.1077

This is an open-access article distributed under the terms of the Creative Commons Attribution Non-Commercial License

(http://creativecommons.org/licenses/by-nc/4.0/), which permits unrestricted non-commercial use, distribution, and reproduction in any medium,

provided the original work is properly cited. 
the whole building to have certain aesthetics. The construction unit shall manage construction materials and materials before construction, purchase construction materials in a unified manner, strictly check the quality of materials, and determine the quantity and type of materials purchased according to the construction progress; take protective measures for curtain wall panel transportation; after the curtain wall is installed, the surplus materials can be preserved properly to avoid material waste.

\section{The building curtain wall construction management work}

\subsection{The management of curtain wall construction drawings}

The construction drawings need to be managed in the early stage of building curtain wall construction. The main points are as follows: (1) Curtain wall construction personnel should be familiar with curtain wall construction drawings in advance, fully understand the design ideas of designers, and clarify the design details at different construction stages; (2) Actively organize construction units, design units and supervision units to go deep into the construction site, and analyze the actual situation of the construction site to optimize the construction drawings and avoid design changes. The technical management personnel of the construction unit should strengthen the examination of the construction drawings, analyze the design defects existing in the drawings, and determine the design contents of the construction drawings through the communication between the construction unit and the design unit to better guide the construction activities.

\subsection{Quality control of engineering materials}

Ensuring the quality of engineering materials is the basic link to ensure the construction quality. Construction personnel should strictly control the quality of materials such as steel, aluminum formwork, panel and adhesion. Materials with higher mechanical properties such as wind load and weight load should be selected for curtain wall support parts. Materials with stronger properties such as wind load and temperature load should be selected for panel parts, and materials with stronger tensile strength, tear and peel strength should be selected for adhesion parts. These materials should be strictly inspected in terms of model, performance and quality to ensure that all materials in sharp parts meet engineering construction standards. At the same time, construction personnel should strictly control the wall thickness of construction steel and aluminum formwork. For example, the thickness of steel should be greater than $3.5 \mathrm{~mm}$, the thickness of aluminum formwork should be greater than $3 \mathrm{~mm}$ and the wall thickness of joint should be controlled to be greater than $5 \mathrm{~mm}$. For curtain wall engineering, the thickness of stainless steel hanger should be controlled to be greater than $3 \mathrm{~mm}$, and the thickness of aluminum alloy hanger should be greater than $4 \mathrm{~mm}$, and epoxy resin $\mathrm{AB}$ glue should be used to treat bonding parts.

\subsection{Installation technology of building curtain wall embedded parts}

The building curtain wall and the main structure of the building are connected by embedded parts. The installation technical points are as follows: (1) Before installing embedded parts, the embedded parts should be customized according to the design drawings provided by the curtain wall design unit, and the embedded parts can be installed only after the size of the embedded parts is determined to be consistent with the design drawings; (2) Measuring instruments are used to determine the installation position of embedded parts (the error should not exceed $10 \mathrm{~mm}$ ), and spot welding is used to weld the embedded parts on the longitudinal reinforcement of the main structure of the building; After welding the embedded parts to the longitudinal reinforcement, the reliability of the installation quality of the embedded parts will be improved by vibrating and compacting concrete. Because of the height of building curtain wall, the supporting system of curtain wall structure bears a large load under the action of wind load and earthquake load, so it is necessary to use special screws for curtain wall to connect the supporting system with embedded parts and connectors. In the process of installing connectors, the installation position error should be controlled within a reasonable range, and attention should be paid to adjusting the flatness of connectors. Welding quality also affects the stability of curtain wall structure system, so special welding equipment should be used for welding in suitable 
weather. Clean up welding slag in time after welding, and do anti-corrosion treatment on fittings and embedded parts after acceptance.

\subsection{Installation technology of main keel}

The main keel is the most important supporting structure system of building curtain wall. In the process of installing the main keel, it is necessary to place the vertical keel on the connector based on the installation node diagram of the main keel provided by the curtain wall design unit, and then stick the anti-corrosion gasket firmly on the contact surface between the vertical keel and the connector, in order to avoid displacement of the gasket. Then, by adjusting the screwing degree of the special screws, the connection relationship between the main keel column and the fittings is determined, and two positioning axes are led out to provide reference lines for the installation of the main keel. Before installing the secondary keel structure of the main keel frame, the flexible gasket should be pasted on the contact surface of the vertical keel and beam, and then connected with special bolts. After installing the main keel, the keel method and lightning protection measures should be done in time. After installation, the installation quality shall be checked and accepted in time. The key process of curtain wall construction when installing curtain wall panel. Before installing the curtain wall panel, the installation quality of the main keel of the curtain wall should be inspected first, and the panel installation can be started when the inspection results meet the construction standards. The installation sequence of curtain wall panels is from top to bottom. During the installation process, the verticality and levelness of the panels are adjusted by the pull-wire method, and the seam width between the panels is strictly controlled. Finally, fixed rainwater is sprayed on the contact surface of curtain wall panels and supporting structure system, which is prone to chemical reaction. Using anti-corrosion technology can significantly improve the corrosion resistance of metal connectors and embedded parts. Anti-corrosion technologies mainly include hot dip galvanizing technology, coating technology, anodic oxidation technology, etc.

\subsection{Discussion on the design points of architectural glass curtain wall}

In case of fire, the ordinary glass curtain wall will often be broken, which will lead to the rapid spread of fire, and even cause people to die and property losses. In this case, in the process of building glass wall design, more attention should be paid to fire protection design. In view of the gap between glass curtain wall and each floor, beam and partition wall, fireproof rock wool with a thickness of not less than $200 \mathrm{~mm}$ should be used to fill it, and galvanized steel plate support with a thickness of not less than $1.5 \mathrm{~mm}$ should be set outside. The gap between steel plate and main structure and curtain wall structure should be filled with fireproof sealant, and then the surface of fireproof sealant should be sealed with weather-resistant adhesive to prevent the fireproof sealant from aging and failure, which can prevent smoke in case of fire. The height of fireproof sealing up and down between layers shall not be less than $1200 \mathrm{~mm}$ (not less than $800 \mathrm{~mm}$ when indoor fireproof spraying system is provided). The interlayer structure of curtain wall shall be provided with fireproof isolation barriers made of incombustible materials, and shall be closed in a ring around the building. Fire curtain wall design shall be adopted for the glass curtain wall in the fire zone of the building and fire glass shall be used for the glass panel, flame retardant fire-proof adhesive tape. In addition, fire sealant shall be used for the rubber strip, and steel keel shall be used for the keel to avoid causing large-scale fire. When designing building glass curtain wall, wind pressure resistance design is important to keep good performance under the influence of wind pressure. Based on this, more attention should be paid to the application of professional design software in actual design, fully combine the actual situation to establish a perfect design model, scientifically and reasonably design the wind pressure deformation coefficient of the components and modules used in the curtain wall. It is also necessary to analyze the environmental impact of the outer wall of the glass curtain wall, so as to better ensure the design strength of the glass curtain wall to reach the standard and enhance its safety and reliability. In the case of earthquake, the glass wall is easily damaged, so in order to reduce the damage, it is necessary to ensure strong displacement resistance and deformation resistance. First of all, in the design, reasonable calculation should be made for each split 
connection position of the building glass curtain wall. For example, sufficient activity allowance should be reserved for the connection part of the connecting piece and the vertical keel to improve the seismic performance of the glass curtain wall. Secondly, it is necessary to ensure that the whole connection of the glass curtain wall can achieve three-dimensional adjustment, improve the elasticity of the wall under earthquake conditions, absorb the displacement of the main structure, and ensure the safety of the curtain wall while giving full play to its functions.

\subsection{Organizational behavior control}

The quality control of architectural curtain wall decoration engineering should run through the whole construction stage, and better manage the preparatory work in the early stage of construction, the construction technology in the construction stage and the quality control at the end of construction. The preparatory work in the early stage of construction should focus on perfecting construction drawings and determining construction links. On the one hand, it should clarify the feasibility of drawings, improve the design of building curtain wall waterproof, fire prevention and lightning protection, and explain the construction site and construction scheme in detail; on the other hand, the plan for the construction link should be based on the actual situation, comprehensively consider the potential safety hazards caused by environmental and human factors in the construction process, and formulate emergency plans to solve the emergencies of the construction project. In the construction stage, attention should be paid to the control of construction technology quality, check whether the construction behavior is carried out according to the original plan in real time, and control the possible human factors in the construction process to ensure the quality and efficiency of the whole construction process. At the end of the construction, the control of the acceptance link should be strengthened to, strictly carry out the acceptance work in accordance with the national and construction industry standards, and then improve the organizational behavior. The quality of construction technology directly determines the construction quality of the whole building curtain wall project, and the construction personnel should control the construction technology quality to ensure that the service life of the building is prolonged. Construction enterprises should define the standards of construction quality and master the technologies of wall three-dimensional design component connection, fire prevention and lightning protection, measure the height, inclination and verticality of the main building and evaluate it strictly according to the standards, and place the reference line on the basis of combining the dimensions of the main building with the construction drawings. Once the grid deviates, it should be adjusted in time to avoid the deviation of curtain wall installation accuracy in the later period which affects the overall construction quality.

\section{Conclusion}

Building curtain wall construction technology and construction quality are hot topics in curtain wall construction activities, and management plays a great role in building curtain wall construction, which needs to be paid attention to.

\section{References}

1. Liu Z. Research on problems existing in construction and design of building curtain wall (in Chinese). Mass Standardization 2019; (6): 26+28. doi: 10.3969/j.issn.1004-9207.2015.06.025.

2. Kribinur A. New technology and construction analysis of architectural decoration (in Chinese). Jushe 2019; (08): 21.

3. Chen L. Quality problems and control management of building curtain wall construction (in Chinese). Home 2019; (7): 133.

4. Qin X. Effective use of building materials in building facade design (in Chinese). Housing and Real Estate 2020; (15): 107.

5. Liu W. Application of Green Energy Saving Technology in Curtain Wall Design of Public Buildings (in Chinese) Green Building Materials 2020; (5): 43+45.

6. Zheng Y. Analysis of urban renewal strategy of existing buildings: Taking the renovation of Yangzi Building in Xinjiekou as an example (in Chinese). Mass Standardization 2020; (9): 65-66. 